See discussions, stats, and author profiles for this publication at: https://www.researchgate.net/publication/349254532

\title{
Celiac Disease as a Rare Cause of Membranous Nephropathy: A Case Report
}

Article in Cureus · February 2021

DOI: $10.7759 /$ cureus.13312

2 authors, including:

$$
\begin{aligned}
& \text { Pedro Vieira } \\
& \text { Hospital Central do Funchal } \\
& 16 \text { PUBlications } 8 \text { CITATIONS }
\end{aligned}
$$

SEE PROFILE 


\title{
Celiac Disease as a Rare Cause of Membranous Nephropathy: A Case Report \\ Nicole Pestana ${ }^{1}$, Carlota Vida ${ }^{1}$, Pedro Vieira ${ }^{1}$, José Durães ${ }^{1}$, Gil Silva ${ }^{1}$ \\ 1. Nephrology Department, Hospital Central do Funchal, Funchal, PRT
}

Corresponding author: Nicole Pestana, nicole.pest@gmail.com

\begin{abstract}
Membranous nephropathy is the most common cause of nephrotic syndrome in adults. A non-negligible number of cases are associated with systemic conditions. We report a case of a 50-year-old man who presented with nephrotic syndrome six months after being diagnosed with celiac disease. Although the patient showed disappearance of circulating immunoglobulin A (IgA) anti-tissue transglutaminase antibodies following a gluten-free diet, he had a sudden onset of nephrotic syndrome presenting with severe hypoalbuminemia. Other secondary causes were promptly excluded leading to the assumption of celiac disease-associated membranous nephropathy with remission after treatment with angiotensin system blockade and a gluten-free diet. The goal of this case report is to alert the clinic towards this rare association aiming for an early diagnosis and adequate selection of long-term therapy.
\end{abstract}

Categories: Internal Medicine, Gastroenterology, Nephrology

Keywords: membranous nephropathy, celiac disease, nephrotic syndrome

\section{Introduction}

Membranous nephropathy (MN) is the most common cause of nephrotic syndrome in white Caucasian adults, accounting for approximately $40 \%$ of cases [1]. MN is classically divided into two subgroups: primary and secondary MN. Secondary MN constitutes around 20\% of all MN cases and occurs in the context of underlying conditions, namely malignancies, drugs, rheumatological diseases, and infections [2]. Celiac disease (CD) is one of the most common autoimmune disorders, with a reported prevalence of $0.5-1 \%$ of the general population [3]. Although the incidence of renal disease in $\mathrm{CD}$ patients is low and vice versa, this association has pathogenic aspects that can affect both conditions. Here we report a case of MN in a patient with $\mathrm{CD}$ and discuss the pitfalls of underlying investigation in this glomerular disease.

Review began 01/12/2021 Review ended 02/12/2021 Published 02/12/2021

(c) Copyright 2021

Pestana et al. This is an open access article distributed under the terms of the Creative Commons Attribution License CC-BY 4.0., which permits unrestricted use, distribution, and reproduction in any medium, provided the original author and source are credited.

\section{Case Presentation}

The authors present a case of a 50-year-old Caucasian man with CD diagnosed in January 2020 and heavy smoking habits (>25 cigarettes a day). He was referred to Nephrology Department in June 2020 due to recent onset of generalized edema with an $8 \mathrm{~kg}$ weight gain and deterioration of renal function. On physical exam he was normotensive and presented with bilateral pitting edema. Laboratory findings revealed decreased renal function (serum creatinine $1.5 \mathrm{mg} / \mathrm{dL}$ as opposed to six months earlier $1 \mathrm{mg} / \mathrm{dL}$ ), severe hypoalbuminemia (albumin $17 \mathrm{~g} / \mathrm{L}$ ) and hypertriglyceridemia (triglycerides $550 \mathrm{mg} / \mathrm{dL}$ ). Urinary analysis showed proteinuria $(4+)$ with a $24 \mathrm{~h}$ urine protein excretion of $30 \mathrm{~g}$. Kidney ultrasound was unremarkable with normal kidneys. Considering a full-blown nephrotic syndrome with massive proteinuria, a renal biopsy was performed revealing a membranous nephropathy (Figure 1). 


\section{Cureus}

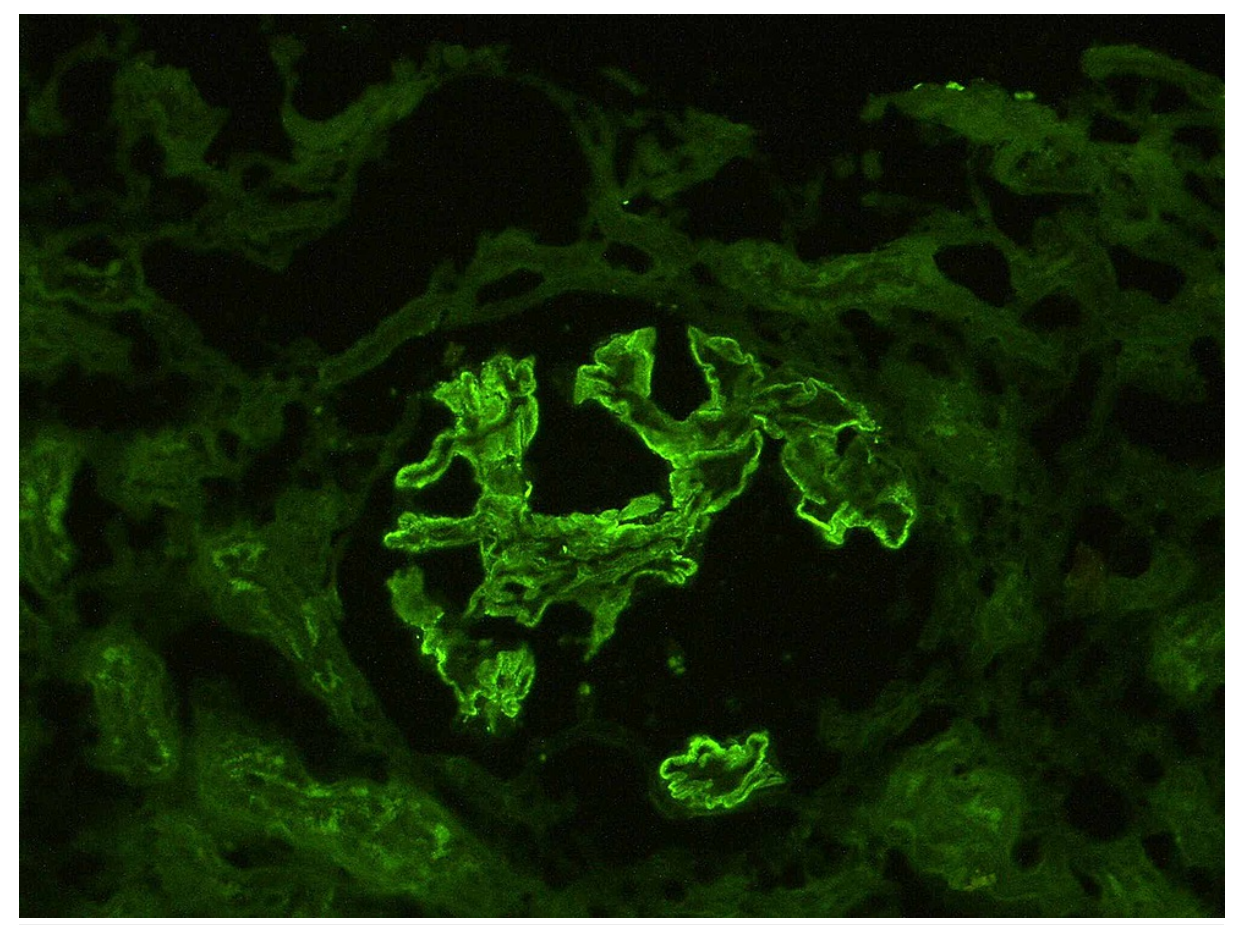

\section{FIGURE 1: Immunoflurorescence microscopy}

Granular deposition of IgG along the outer surface of capillary walls

Given his known $\mathrm{CD}$ and possible relationship with glomerulonephritis, analytical investigation was extended and revealed disappearance of circulating immunoglobulin A (IgA) anti-tissue transglutaminase antibodies following a six-month gluten-free diet. At this point, the hypothetical diagnosis of secondary MN due to $\mathrm{CD}$ was temporarily postponed to exclude other further MN causes. Additional analysis revealed a low titer of antinuclear antibodies (ANA; with a non-specific nucleolar pattern) (titer 1:320) and negative antidouble-stranded DNA, rheumatoid factor, complement, anti-neutrophil cytoplasmic, and anti-

phospholipase A2 receptor antibodies (anti-PLA2R). Supplementary studies to characterize the ANA pattern did not reveal any specific disease-associated autoantibodies. Nailfold capillaroscopy was performed, excluding Raynaud's phenomenon. Hepatitis B, C, and HIV were also excluded. Thoracic and abdominal computed tomography scan, colonoscopy, and endoscopy were negative. Regarding his past medical history, the patient had never received gold salts or nonsteroidal anti-inflammatory drugs. Considering the exclusion of other secondary causes, the assumption of MN secondary to $\mathrm{CD}$ was made. A conservative approach was initiated by ramipril until $15 \mathrm{mg}$ a day in addition to a gluten-free diet. Rituximab was considered but considering partial remission in two months to proteinuria under $6 \mathrm{~g} /$ day, the approach remained conservative. Although the low evidence of MN and $\mathrm{CD}$ association reported, the presentation of full blow nephrotic syndrome following $\mathrm{CD}$ diagnosis and the response to a gluten-free diet supported the diagnosis of CD-associated MN.

\section{Discussion}

The association between $\mathrm{CD}$ and $\mathrm{MN}$ is rarely reported in the literature [4]. As both are immune-mediated diseases, they possibly share an autoimmune pathogenesis with simultaneous digestive and renal involvement. Some described an increase in the number of cases of chronic glomerulonephritis and renal insufficiency in patients with $\mathrm{CD}$ and this risk is greater in adults [5]. By far the main association between $\mathrm{CD}$ and glomerular disease is IgA nephropathy (IgAN) with $22-77 \%$ of patients with IgAN having IgA antigliadin antibodies and 3-4\% of these having $\mathrm{CD}[6,7]$. In our case report the patient had histological evidence of MN but no IgA deposits, excluding any resemblance to IgAN. In our opinion, the link between $\mathrm{CD}$ and $\mathrm{MN}$ is not unexpected. Although there was a different temporal onset of both diseases the patient had remission of massive proteinuria followed by disappearance of circulating IgA anti-tissue transglutaminase antibodies. In fact, there was remission of both diseases, as is seen in the majority of cases of secondary MN that remit when the original cause is addressed [8]. Anti-PLA2R autoantibodies are highly specific for primary MN and are found in approximately $75 \%$ of patients at time of diagnosis [9]. We would like to emphasize that our patient had negative anti-PLA2R leading us to secondary investigation as recommended by the 2012 Kidney Disease Improving Global Outcomes (KDIGO) guidelines [10]. ANAs have also been found in autoimmune diseases and cancer [11,12]. Its presence although unspecific alerts us to the possibility of systemic lupus erythematosus (SLE) which has a known association with CD [13], and systemic sclerosis (SS). The absence of clinical evidence of SLE (arthralgias, cutaneous lesions, photosensitivity, 
telangiectasia, hematological affection, or active urinary sediment) associated with the negative anti-DNA antibodies excludes this diagnosis. In addition, the absence of Raynaud's phenomenon, skin changes, and unexplained dry month and eyes associated with negative specific antibodies disease do not contribute to the diagnosis of SS nor Sjogren syndrome. Considering this, concerns of neoplasms were raised. Cancer diagnosis accounts for $10 \%$ of secondary cases of MN, with lung and gastrointestinal systems the most frequent [14]. These are sometimes diagnosed in a non-specific nucleolar ANA pattern without identified autoantibody [12]. Regarding the patient's heavy smoking habits, MN-associated neoplasia was promptly studied and excluded. We concluded our investigation with exclusion of specific MN-implicated drugs (gold salt drugs and anti-nonsteroidal anti-inflammatory drugs). The assumption of secondary MN associated with CD was made with the patient entering partial remission after two months of increasing angiotensin blocker therapy and continuous gluten-free diet. Literature supports our case report in which the absence of anti-PLA2R is associated with a higher likelihood of clinical remission [15].

\section{Conclusions}

Clinicians should be aware of the rare association between CD and MN. This must be considered in a patient presenting with improvement of nephrotic syndrome after angiotensin blockage therapy and gluten-free diet, despite the absence of IgA anti-tissue transglutaminase antibodies. Further studies are necessary to elucidate the possible common pathogenic mechanisms of both diseases.

\section{Additional Information}

\section{Disclosures}

Human subjects: Consent was obtained or waived by all participants in this study. Conflicts of interest: In compliance with the ICMJE uniform disclosure form, all authors declare the following: Payment/services info: All authors have declared that no financial support was received from any organization for the submitted work. Financial relationships: All authors have declared that they have no financial relationships at present or within the previous three years with any organizations that might have an interest in the submitted work. Other relationships: All authors have declared that there are no other relationships or activities that could appear to have influenced the submitted work.

\section{References}

1. Johnson R, Feehally J, Floege J, Tonelli M: Comprehensive Clinical Nephrology. Elsevier, Amsterdam; 2018. https://www.elsevier.com/books/comprehensive-clinical-nephrology/johnson/978-0-323-47909-7.

2. Couser WG: Primary membranous nephropathy. Clin J Am Soc Nephrol. 2017, 12:983-997. 10.2215/CJN.11761116

3. Caio G, Volta U, Sapone A, Leffler DA, De Giorgio R, Catassi C, Fasano A: Celiac disease: a comprehensive current review. BMC Med. 2019, 17:142. 10.1186/s12916-019-1380-z

4. Gimenez Llort A, Vila Cots J, Camacho Diaz JA, Vila Santandreu A, Concheiro Guisan A, Garcia Garcia L: Nephrotic syndrome associated with celiac disease. A report of five cases . Nephron. 2002, 92:950. $10.1159 / 000065576$

5. Ludvigsson JF, Montgomery SM, Olen O, Ekbom A, Ludvigsson J, Fored M: Coeliac disease and risk of renal disease-a general population cohort study. Nephrol Dial Transplant. 2006, 21:1809-15. 10.1093/ndt/gfl117

6. Sategna-Guidetti C, Ferfoglia G, Bruno M, Pulitano R, Roccatello D, Coppo R: Do IgA antigliadin and IgA antiendomysium antibodies show there is latent coeliac disease in primary IgA nephropathy?. Gut. 1992, 33:476-8.

7. Almroth G, Axelsson T, Müssener E, Grodzinsky E, Midhagen G, Olcén P: Increased prevalence of antigliadin IgA-antibodies with aberrant duodenal histopathological findings in patients with IgA-nephropathy and related disorders. Ups J Med Sci. 2006, 111:339-52. 10.3109/2000-1967-060

8. Soro S, Sánchez de la Nieta MD, Rivera F: Coeliac disease and membranous nephropathy . Nefrología. 2009, 29:479-481. 10.3265/Nefrologia.2009.29.5.5324.en.full

9. Mastroianni-Kirsztajn G, Hornig N, Schlumberger W: Autoantibodies in renal diseases - clinical significance and recent developments in serological detection. Front Immunol. 2015, 6:221. 10.3389/fimmu.2015.00221

10. Cattran DC, Feehally J, Cook HT, et al.: Kidney Disease: Improving Global outcomes (KDIGO) glomerulonephritis work group. KDIGO clinical practice guideline for glomerulonephritis. Kidney Int Suppl. 2012, 2:139-274. 10.1038/kisup.2012.9

11. Solomon DH, Kavanaugh AJ, Schur PH: Evidence-based guidelines for the use of immunologic tests: antinuclear antibody testing. Arthritis Care Res. 2002, 47:434-444. 10.1002/art.10561

12. Imai H, Ochs RL, Kiyosawa K, Furuta S, Nakamura RM, Tan EM: Nucleolar antigens and autoantibodies in hepatocellular carcinoma and other malignancies. Am J Pathol. 1992, 140:859-70.

13. Collin P, Mäki M: Associated disorders in coeliac disease: clinical aspects . Scand J Gastroenterol. 1994, 29:769-75. 10.3109/00365529409092508

14. Lefaucher C, Stengel B, Nochy D, Martel P, Hill GS, Jacquot C, Rossert J: Membranous nephropathy and cancer: epidemiologic evidence and determinants of high cancer association. Kidney Int. 2006, 70:1510-7. 10.1038/sj.ki.5001790

15. Pourcine F, Dahan K, Mihout F, Cachanado M, Brocheriou I, Debiec H, Ronco P: Prognostic value of PLAR2 autoimmunity detected by measurement of anti-PLAR antibodies combined with detection of PLA2R antigen in membranous nephropathy: a single centre study over 14 years. PloS One. 2017, 12:00173201. 10.1371/journal.pone.0173201 